\title{
Natural Antimicrobial Peptides: Pleiotropic Molecules in Host Defense
}

\author{
Mercedes Leonor Sánchez ${ }^{1,2}$, Melina María Belén Martínez ${ }^{3}$, Paulo César Maffia ${ }^{1,3^{*}}$ \\ ${ }^{1}$ National Council for Scientific Research (CONICET), Buenos Aires, Argentina \\ ${ }^{2}$ School of Medicine, University of Buenos Aires, Buenos Aires, Argentina \\ ${ }^{3}$ Laboratory of Molecular Microbiology, National University of Quilmes, Buenos Aires, Argentina \\ Email: *paulo.maffia@unq.edu.ar
}

Received July 24, 2013; revised August 24, 2013; accepted September 24, 2013

Copyright (C) 2013 Mercedes Leonor Sánchez et al. This is an open access article distributed under the Creative Commons Attribution License, which permits unrestricted use, distribution, and reproduction in any medium, provided the original work is properly cited.

\begin{abstract}
Natural antimicrobial peptides (AMPs) are small cationic molecules that display antimicrobial activity against a wide range of bacteria, fungi and viruses. AMPs are multifunctional molecules that have an essential activity in infection and inflammation: they play an important role in the innate immune response, not only as antimicrobial agents, but also as immunomodulating molecules and as an important link between the innate and adaptive immune response. In this article, we will discuss the antimicrobial activity, together with the novel properties of some of these molecules as immune modulators on the innate and adaptive immune response.
\end{abstract}

Keywords: Antimicrobial Peptides; Immune Response; Cathelicidins; Defensins; SLPI

\section{Introduction}

Adaptive immune response is considered critical to prevent the establishment or progression of infections by parasites, bacteria and viruses. But it is the innate immunity that is responsible for the rapid initial defense against the pathogen.

The co-evolution of hosts and pathogens has led to a diverse group of peptides that the host produces in order to kill or reduce the infective microbes. These peptides, called antimicrobial peptides (AMPs) can be found in almost all forms of life, in organisms like bacteria or plants and also in invertebrate and vertebrate species, including mammals. Among the latter, humans have several cell types that synthesize and secrete AMPs, such as epithelial cells, epidermal keratinocytes, neutrophils, macrophages, and natural killer cells. In mammals, these AMPs can be considered as part of the innate immune system.

Most of the AMPs are generally expressed as propeptides that undergo subsequent proteolytic process to release the biologically active and mature host defense peptide. Some AMPs are constitutively expressed but others are synthesized upon infection signals such as various exogenous and endogenous inflammatory me-

\footnotetext{
"Corresponding author.
}

diators [1,2].

Classically, AMPs are short, amphiphilic, and mostly cationic polypeptides with a diverse repertoire of activities within the innate immunity system. These multifaceted molecules may be able to enhance phagocytosis, stimulate prostaglandin release, neutralize the septic effects of LPS, and promote recruitment and accumulation of various immune cells at inflammatory sites among other functions $[3,4]$.

In recent years, these molecules have been the center of attention, because of their promising uses as alternative approaches to infection management.

AMPs are mainly cationic and amphipathic peptides; two characteristics together with their conformational flexibility and secondary structure allow them to interact with and insert into biomembranes, leading to disruption of cytoplasmic membrane integrity. AMPs can also interact with intracellular bacterial targets, resulting in microbial killing [5]. In general, cationic peptides interfere with bacterial membrane integrity such as membrane wrinkling and the formation of ion-permeable channels that probably increase membrane permeability and finally lead to bacterial cell lysis.

It is also worthy to notice that it has recently been shown that bacteria are capable of adapting and resisting host AMPs, by means of production of peptidases and 
proteases that degrade antimicrobial peptides, or compounds that inhibit their action, and also by reduction of net anionic charge of the bacterial cell envelope. The relationship between antibacterial peptides and cell wall targets may shed light in strategies to challenge antibiotic resistance.

However, even though these host defense peptides originally gained prominence through initial descriptions of their direct antimicrobial functions [5], not all protective cationic peptides are necessarily working through direct microbicidal action. In contrast, under such conditions, a wide range of functions have been demonstrated for these peptides in the context of host immunity, as will be discussed in this review.

Some AMPs are involved in the transition to the adaptive immune response, as they were shown to be chemotactic for human monocytes [6], T cells [7], modulating dendritic cell differentiation and dendritic cell-induced $\mathrm{T}$ cell polarization [8]. However, some of them can also function as negative feedback regulators facilitating the resolution of inflammation [9]. Therefore, it is possible that a malfunction of the feedback control, i.e. through a decreased secretion of AMPs that participates as negative feedback regulator, can amplify and perpetuate the inflammatory process.

As we mentioned, the role of AMPs in innate immunity and the pathogen target has been very well studied, but it is less known the ability of them to induce not only a $\mathrm{T}$ helper cell response, but also an appropriate $\mathrm{T}$ cells response. This is a very important issue, since an appropriate $\mathrm{T}$ cell response, i.e. Th1 and Th2 for intracellular and extracellular pathogens respectively, will aid the resolution or perpetuation of the infection. In this review, we have chosen only three AMPs: cathelicidins, defensins and SLPI, to describe the typical functions and to illustrate their ability to modulate the immune response.

\section{AMPs Categories}

Host defense peptides can be organized into three basic categories regarding the target: 1) plasma membraneactive peptides are thought to act in a multistage process where they electrostatically bind to a membrane surface, aggregate to form superstructures, and disrupt membrane integrity; 2) a second group of peptides act on intracellular targets to inhibit transcriptional, translational or other processes; and 3) cell wall-active peptides target precursors, mechanisms, and/or essential intermediates in peptidoglycan, lipopolysaccharide (LPS) or other biosynthetic pathways interfering with functional cell wall synthesis and ensuing bacterial replication.

\section{Eukariotic Peptides}

When the first eukaryotic defensin peptides were charac- terized nearly 30 years ago, mechanism of action studies indicated that these molecules were able to rapidly and efficiently permeabilize artificial membrane bilayers [10].

Eukaryotic peptides are typically small and cationic, and are structurally classified into five major groups: 1) cysteine-stabilized (e.g., defensins); 2) cysteine-stabilized loop (e.g., protegrins, tachyplesins); 3) linear $\alpha$ helical (e.g., LL-37, kinocidin helices); 4) enriched in one or more specific amino acid residues (i.e., Bac5); or 5) combinations of the above. Although certain families of host defense peptides, particularly those of higher eukaryotes, show evidence of extensive gene duplication, and in some cases positive selection, their structural (cysteine stabilization, $\alpha$-helicity) and biophysical (amphipathicity, cationicity) features are often highly conserved.

\section{Defensins}

Defensins are cationic AMPs produced at a variety of epithelial surfaces by various cells as a component of the innate host defense. They are cyclic peptides which are categorized into three subfamilies on the basis of the disulfide pairings between their six conserved cysteine residues ( $\alpha$ - and $\beta$-defensins) or their macrocyclic nature ( $\theta$-defensins). The $\alpha$ - and $\beta$-defensins are widely distributed in vertebrate species, whereas $\theta$-defensins have so far been identified only in Old World monkeys and apparently only in neutrophils and monocytes [11,12]. In mammalian species, around $50 \alpha$-defensins and $90 \beta$ defensins have been identified which are either stored in the granules of neutrophils and Paneth cells, or are generated by monocytes/macrophages, keratinocytes or epithelial cells of the respiratory, digestive, urinary and reproductive systems $[13,14]$.

$\alpha$ - and $\beta$-defensins modify cell migration and maturation, induce cytokines and trigger histamin and prostaglandin D2 release from mast cells. $\beta$-defensins are chemoattractive for immature dendritic cells and memory T cells.

The production of defensins is regulated by pathogens or by inflammatory cytokines released at the site of inflammation. For example, alpha-defensins can be released upon microbial invasion or up-regulated by stimulation with lipopolisaccharides and tumor necrosis factor- $\alpha$ [15]. The $\beta$-defensins, found in epithelial cells as well as monocytes/macrophages and dendritic cells, is up-regulated in bacterial infections through the recognition of bacterial components by the Toll-like receptor (TLR) [16-19]. The production and secretion can be also modulated by other AMPs. For example, the human cathelicidin LL37 can synergize with IL-1 $\beta$ to increase the production of IL- 6 , IL-8, IL-10, CCL2, as well as to increase the synthesis and release of $\alpha$-defensins [20,21]. 
On the contrary, downregulation of defensins can be induced by endogenous glucocorticoids leading to increased severity of group A Streptococcus pyogenes skin infection [22]. It was also demonstrated that the inactivation of the antimicrobial activity of $\beta$-defensins contributes with the recurrent airways infections in patients with cystic fibrosis [23,24].

The antimicrobial activity of defensins has been determined in Staphylococcus aureus, Pseudomonas aeruginosa, Salmonella and certain enveloped viruses [25,26]. This antimicrobial function is supported by experiments performed in knocking-out $\beta$-defensin 1 mice [27].

AMPs constitute a substantial part of the mucosal barrier, and $\beta$-defensins are the principal type secreted by the epithelium. The four well-characterized human $\beta$ defensins, hBD-1-4, encoded by $\beta$-defensin 1 (DEFB1), DEFB4, DEFB103, and DEFB104, are small (30 - 47 amino acid), cationic, cysteine-rich peptides that possess broad antimicrobial activity [28].

The antimicrobial activity is potentiated under reducing conditions that exist in the hypoxic gut lumen, whereas other antimicrobial peptides, such as hBD-3, are diminished in the reduced state.

The expression of hBD-1 is constitutive, whereas other defensins are expressed in response to microbial and inflammatory stimuli. Defective expression of hBD-1 is associated with mucosal diseases, such as inflammatory bowel disease, candidia carriage, periodontitis, and dental carries.

DEFB114 is a $\beta$ defensin that exhibited a broad spectrum of antimicrobial activity against typical pathogenic microbes. This AMP also demonstrated to have LPS binding activity while inhibiting the release of TNF- $\alpha$ in RAW264.7 culture when challenged with LPS through the inhibition of MAP kinase p42/44. This peptide also displayed antimicrobial activity against typical pathogens, i.e., Escherichia coli, Staphylococcus aureus, and Candida albicans, while showing low cytotoxicity toward human erythrocytes. All these features are indicative of its potential therapeutic use in the treatment of LPS-induced inflammation [29].

Besides inhibiting microbial growth, an additional function of some of these AMPs is their influence on the immune response by recruiting leukocytes through the induction of chemokines such as CXCL8 (IL-8), CCL2 (MCP-1), IP-10, MIP3 $\alpha$, RANTES and cytokines such as IL-6, IL-10, IL-18, IFN $\gamma$ and IFN- $\alpha$. Cells that can be recruited and activated by defensins are neutrophils, monocytes, macrophages, immature dendritic cells, mast cells and T cells [30-32]. Therefore, defensins can tailor the adaptive immune response even by inducing the expression of the costimulatory molecules CD80, CD86 and CD40 on monocytes and dendritic cells [31].

Antigen specific cytotoxic $\mathrm{T}$ lymphocytes can be in- duced by $\alpha$-defensins and murine $\beta$-defensins, thereby enhancing Th1-dependent cellular responses, and potentially anti-tumour immunity [33,34].

However, systemic injections of human $\alpha$ defensins into mice result in augmentation of both Th1 and Th2 immune responses [35]. Whether human $\beta$ defensin also induce a Th1 and Th2 immune response it is less known since human $\beta$ defensins are inactive in mice. Experiments with murine $\beta$ defensins (MBDs) in mice suggest that these defensins induce mainly a Th1 response [36].

On the other hand, it was shown that human defensins co-administered with antigens in mice resulted in an increased production of antibodies, providing evidence of the role of these peptides in humoral response [37]. Other functions of defensins have been deeply discussed by Oppenheim [36]. Based on these findings, it seems that the action of defensins on $\mathrm{T}$ cell responses is not specific, since these peptides enhance both cellular and humoral cytokine production and immune responses.

As it was mentioned above, a less beneficial effect of $\beta$-defensins is also suggested, since $\beta$-defensins could amplify inflammation by binding CCR6 expressed by Th17 cells [38,39].

In 2008, a study by Sass et al. [40], evaluated the antibiotic mode of action of $\beta$-defensin (h $\beta \mathrm{D}-3)$ against Staphylococcus aureus. They showed that $\mathrm{h} \beta \mathrm{D}-3$ induces alterations in the $S$. aureus core cell wall stress regulon in a similar fashion to the cell wall-active antibiotic vancomycin. This observation is consistent with the concept that $\mathrm{h} \beta \mathrm{D}-3$ perturbs specific component(s) of the cell wall, triggering upregulation of cell wall stress response pathways. Further, h $\beta$ D-3 inhibits purified enzymes required for cell wall synthesis. Finally, transmission electron microscopy revealed that exposure to $\mathrm{h} \beta \mathrm{D}-3$ causes apparent fissures in the cell wall that allowed for protrusions of membrane bound cytoplasmic contents of $S$. aureus.

\section{Cathelicidin}

The name cathelicidin comes from the highly conserved $\mathrm{N}$-terminal region of these proteins known as the cathelin domain. This protein contains two disulfide bonds between cysteine residues C85-C96 and C107-C124 [41] and was given its name based on an ability to inhibit the protease cathepsin-L. The cathelicidin LL-37 is the only member of the cathelicidin family expressed in humans [42].

The main source of cathelicidin in the human body is azurophilic granules of neutrophil, but it can also be found in mucosal surfaces and in keratinocytes during inflammation [42]. Another study also demonstrated the increased expression of LL-37 in macrophages, endothelial cells and $\mathrm{T}$ cells in atherosclerotic lesions [43]. 
Unlike defensins, cathelicidin expression in humans is less directly modulated by TLRs or cytokines, but rather relies on the action and modulation of Vitamin $\mathrm{D}$ in specific tissues [44].

Like other AMPs, cathelicidins kill bacteria through permeabilization of bacterial cell membranes and binding to LPS [45]. The microbicidal activity of cathelicidin was further supported by in vivo experiments with cathelicidin knockout mice [46]. Furthermore, cathelicin LL-37 acts on mast cells and increases the expression of TLR4, while releasing histamine, prostaglandins and the cytokines IL-4, IL-5, IL-1 $\beta$ [47] and IL-8 in airway epithelial cells and keratinocytes [48]. Thus, it acts as a chemokine for neutrophils, monocytes, mast cells and T cells but not for dendritic cells [49]. Cathelicidin also suppresses neutrophil apoptosis, and on the other hand promotes apoptosis of epithelial cells [49].

It has been demonstrated that LL-37 is a potent modifier of DC differentiation. LL-37-derived DC displayed significantly up-regulated endocytic capacity, modified phagocytic receptor expression and function, up-regulated co stimulatory molecule expression, enhanced secretion of Th-1 inducing cytokines, and promoted Th1 responses in vitro [50].

However, Kandler et al. showed that LL-37 suppressed the maturation and activation of human dendritic cells in response to a number of TLR ligands and thus the ex vivo costimulation of T cells [51]. Furthermore, LL-37 increased the level of TLR4 and induced the release of Th2 cytokines IL-4, IL-5 and IL- $1 \beta$ from mast cells [47]. Besides, LL37 synergistically enhances the IL-1 $\beta$ induced production of cytokines (IL-6, IL-10) and chemokines such as MCP-1 and MCP-3 in human peripheral blood monocytes [20]. These findings suggest that LL-37 induces mainly a Th2 response.

So far, there is no data on LL-37 and the induction of Th17, although Peric, M. et al. [52] reported that human keratinocytes could increase the expression of cathelicidin when stimulated in the presence of vitamin $\mathrm{D}(3)$ and this increase was signaled through the IL-17RA.

The hCAP-18 prepropeptide is mainly produced in leucocytes and epithelial cells. After secretion, processing to the active AMP occurs by local proteases. As the proteolytic activity of various cells and tissues differs, hCAP-18 can be processed either to the full-length active peptide LL-37 found in the exocytosed material of neutrophils or to multiple smaller peptides such as RK-31 and KS-30, which occur on the skin surface and display increased antimicrobial activity.

In neutrophils, hCAP-18 is stored in the specific granules and, upon degranulation, is processed to LL-37 by protease 3 released from the azurophilic granules. In the skin, RK-31 and KS-30 are produced by the action of SCTE (stratum corneum tryptic enzyme, kallikrein 5/hK5) and SCCE (stratum corneum chymotryptic enzyme, kallikrein $7 / \mathrm{hK} 7$ ). High concentrations of hCAP-18 are present in seminal plasma. Proteolytic cleavage by semenderived gastricsin occurs when the $\mathrm{pH}$ drops in the vagina generating the active peptide ALL-38. Similar to the defensins, cathelicidin peptides exert various immunomodulatory functions. As a striking example for the importance of cathelicidin for human health, LL-37 deficiency was found to be associated with chronic peridontal disease. High levels of hCAP-18/LL-37 are produced in healing human skin suggesting an important role in re-epithelialization during wound healing.

Consistently, healing was inhibited by LL-37 specific antibodies in an organ-cultured human skin model and in chronic ulcers, hCAP-18/LL-37 was found to be absent in ulcer edge epithelium.

Although not a direct measure of microbicidal activity, numerous studies have demonstrated that LL-37 binds LPS with high affinity [53-55] and hence may limit its endotoxic properties as well as downstream immunological signaling events.

In Gram negative bacteria, resistance to cationic antimicrobial peptides is conferred via activation of $\mathrm{PhoP} /$ PhoQ and PmrA/PmrB two component regulatory systems, which lead to increased incorporation of positively charged 1-4-aminoarabinose subunits into LPS and other adaptive responses [56]. This molecular modification results in a more neutral or even cationic surface charge, and hence reduced electrostatic attraction for cationic antimicrobial peptides, affording increased survival of organisms.

Although the above studies are not a direct measure of LL-37's mechanism of action, they do suggest that members of this classical $\alpha$-helical host defense peptides family may have specific interactions with certain Gramnegative cell wall component structures.

\section{SLPI}

Secretory Leukocyte Protease Inhibitor (SLPI) is a serine protease inhibitor of cathepsin G, trypsin and chymotrypsin, but primarily against neutrophil elastase [57]. SLPI was first isolated from bronchial secretions and was later found to be also produced by many mucosal surfaces, keratinocytes, neutrophils and macrophages.

This polycationic non-glycosylated peptide display antimicrobial properties in vivo and in vitro [58,59]. The antimicrobial activity of human SLPI has been described for Escherichia coli, Pseudomonas aeruginosa, Staphylococcus aureus, Staphylococcus epidermidis, Streptococcus sp., Aspergillus fumigatus, Candida albicans, and HIV [58]. It has been recently reported that mouse and even human SLPI shows antibacterial activity against mycobacteria and it constitutes a pattern recognition receptor for mycobateria that not only kills bacteria but 
facilitates their phagocytosis by murine and human macrophages [60]. The antimycobacterial activity of SLPI resides in the WAP (Whey Acidic Protein) domains of the molecule and is quite similar to other cationic peptides [61]. The antimicrobial activity clearly does not depend on inhibition of serine proteases. Instead, disruption of the membranes of target organisms is observed, most likely depending of the cationic nature of these small proteins.

As it was mentioned before, SLPI is constitutively produced by epithelial cells and neutrophils and alveolar macrophages. Its expression is upregulated by diverse inflammatory stimuli such as TNF $\alpha$ and $M$. tuberculosis and downmodulated by adenoviral infection, TGF $\beta 1$ cytokine production and during chronic obstructive lung disease [62-67]. In a recent review, the multifaceted roles of SLPI and elafin/trappin-2 were examined in the context of their possible use as inhaled drugs for treating chronic lung diseases such as CF (cystic fibrosis) and COPD (chronic obstructive pulmonary disease) [68].

\subsection{SLPI as a Biomarker}

Jendeberg et al. measured the antimicrobial peptide concentration in plasma from patients with community-acquired pneumonia (CAP), in this work the authors found that in subjects with CAP, mean plasma concentrations of SLPI and bactericidal/permeability-increasing protein (BPI) were significantly higher than in healthy control subjects, but less markedly increased in patients with non-respiratory tract infections. The finding of higher SLPI levels in male subjects with CAP implies that there are sex-dependent immunological differences in SLPI turnover [69].

The relationships between rhinovirus infection and bacterial infection and the role of antimicrobial peptides in COPD exacerbations were also investigated. In this studies the antimicrobial peptides SLPI, elafin, pentraxin, LL-37, $\alpha$-defensins and $\beta$-defensin-2, and the protease neutrophil elastase were evaluated. The authors concluded that neutrophil elastase was significantly increased and SLPI and elafin significantly reduced after rhinovirus infection exclusively in subjects with COPD with secondary bacterial infections, and SLPI and elafin levels correlated inversely with bacterial load. Rhinovirus infections are frequently followed by secondary bacterial infections in COPD and cleavage of the antimicrobial peptides SLPI and elafin by virus-induced neutrophil elastase may precipitate in these secondary bacterial infections. Therapy targeting neutrophil elastase or enhancing innate immunity may be useful novel therapies for prevention of secondary bacterial infections in virusinduced COPD exacerbations [70].

\subsection{SLPI as Anti-Inflammatory Molecule}

Besides the antimicrobial activity, SLPI major function is to inhibit inflammation by blocking the proteolitic activity of serine proteinases released by leukocytes and also through downmodulating several cytokines up-regulated via LPS such as TNF $\alpha$, MCP-1 and IL-6 [71-75].

The anti-inflammatory activity is also mediated by inhibition of proteolitic degradation of IkB and the activation of the transcription factor nuclear factor NFkB [75, 76]. Moreover, SLPI knock out mice show impaired cutaneous wound healing with increased activation of local TGF $\beta$ [77].

The role of SLPI in adaptive immunity is less clear. Samsom et al. proposed that SLPI expression in dendritic cells located in cervical lymph node contributes to mucosal tolerance [78]. Furthermore, SLPI modulates antibody class switching by dampening IgG and IgA class switching recombination without affecting B cell proliferation [79]. However, splenic B cells from SLPI knock out mice have higher proliferation rates and produce higher levels of IgM [80]. Overall these data indicate that SLPI may affect adaptive immune response, however, it is not known whether SLPI might affect directly the classical Th1 or Th2 pattern of cytokines.

Another serine protease inhibitor of the same family of SLPI, named ELAFIN, can activate lung dendritic cells and produce a bias to Th1 response, in an in vivo murine model [81]. Moreover, it was suggested that SLPI could also favour a Th1 response, since SLPI can inhibit LPS-induced production of PGE2 from monocytes and PGE2 skews T-helper lymphocyte cytokine production towards a Th2 immune response [82]. However, this data does not agree with the suppression of inflammation observed in an arthritis mouse model [83]. The activity of SLPI on adaptive immune response seems to be complex. It was observed that SLPI-treated human peripheral mononuclear cells may release Th2 cytokines. Therefore, further studies are required to clarify the role of SLPI in $\mathrm{T}$ helper cells immune response.

Although not yet understood in detail, SLPI was demonstrated to be a pivotal endogenous factor necessary for optimal cutaneous and mucosal wound healing, most likely due to its antiprotease activity $[77,84,85]$.

\subsection{SLPI in HPV and HIV Infection}

Hoffmann, M., et al demonstrated that exposure of human cervical epithelial cells to high-risk human papillomaviruses results in a reduction in the expression of SLPI [86]. In head and neck squamous cell carcinoma (HNSCC) tissue, HPV DNA was analyzed and correlated with SLPI expression. A possible role of smoking on SLPI expression in clinically normal mucosa was also investigated, 19 patients treated for non-malignant dis- 
eases (non-HNSCC) were analyzed for SLPI expression and correlated with smoking habits. In HNSCC patients, SLPI expression showed a significant inverse correlation with HPV status. For the first time, a correlation between SLPI downregulation and HPV infection was demonstrated, suggesting that high levels of SLPI, possibly induced by environmental factors such as tobacco smoking, correlate with protective effects against HPV infection [87].

Depressed cervicovaginal SLPI levels have been correlated with Trichomonas vaginalis infection. SLPI levels were lower in females with a positive $T$. vaginalis antigen test result, a vaginal $\mathrm{pH}>4.5$, vaginal leukocytosis, and recurrent $T$. vaginalis infection. SLPI level was reduced by $>50 \%$ in a $T$. vaginalis load-dependent manner. The SLPI level could be used as a vaginal-health marker to evaluate interventions and vaginal products [88].

SLPI was identified as a factor responsible for selective anti-HIV activity of human saliva [89]. It appears that this activity results from binding of SLPI to host cell membrane associated proteins such as scramblase and/or annexin II, rather than direct interaction with the virus particle $[90,91]$. SLPI have also been associated with anti-HIV activity of vaginal fluid [92,93]. Mechanistically, SLPI has been shown to inhibit HIV-1 infection of macrophages by binding to and blocking cell surface annexin A2 [34]. Annexin A2 is found at the cell surface as the annexin A2 heterotetramer (A2t) consisting of two annexin A2 monomers and an S100A10 dimer [94,95], which are co-expressed by basal epithelial cells [96]. It was also demonstrated that the annexin A2 heterotetramer (A2t) contributes to HPV16 (the most common high-risk genotype) infection and co-immunoprecipitates with HPV16 particles on the surface of epithelial cells in an L2-dependent manner. Inhibiting A2t with an endogenous annexin A2 ligand, SLPI, or with an annexin A2 antibody significantly reduces HPV16 infection [97].

\subsection{SLPI as a PRR}

The innate immune system of the host is able to detect "pathogen-associated molecular patterns" (PAMPs), conserved molecular structures produced exclusively by microorganisms that are essential for the physiology of microbes [98]. PAMPs are recognized by pattern recognition receptors (PRRs) of the host. Some of them, like TLR2 and TLR4, are present on the cell surface of cells from the innate immune system, in contrast, other PRRs, like TLR3 and TLR7, are found inside the cells. Finally, the last group of known PRRs, such as surfactants and C-reactive protein, are soluble and present in extracellular body fluids. The recognition of PAMPs by PRRs facilitates the uptake of the pathogen or the signaling needed for the induction of the appropriate immune re- sponse of the host $[98,99]$. AMPs are able to bind and kill a pathogen but it is not clear whether most of these peptides could be considered as a PRR, specifically binding to PAMPs and facilitating the clearing by macrophages. Gomez et al. [59] demonstrated that human recombinant SLPI not only kills mycobacteria but also acts as a pattern recognition receptor for the host immune system.

\section{Conclusions}

There is no doubt that AMPs have a microbicidal activity and a role in modulating the immune response. Moreover, some of them, like SLPI, acts like pattern recognition receptors that facilitate the clearing of the pathogens by immune cells.

Therefore, in the era of antibiotic resistance they look as excellent candidates to develop new antimicrobial agents. However, they may elicit an array of different actions on adaptive immune response that it has to be determined before the new drugs become available. The activities of these peptides should be analyzed under different physiological and pathological settings, since the activity may vary depending on the immune response elicited by the pathogen.

Understanding these pleiotropic molecules that function as "natural antibiotics" and "immune regulators" has great promise for yielding new strategies in the control of human disease.

\section{REFERENCES}

[1] R. A. Dorschner, et al., "Cutaneous Injury Induces the Release of Cathelicidin Anti-Microbial Peptides Active against Group A Streptococcus," Journal of Investigative Dermatology, Vol. 117, No. 1, 2001, pp. 91-97. http://dx.doi.org/10.1046/j.1523-1747.2001.01340.x

[2] M. Zasloff, "Inducing Endogenous Antimicrobial Peptides to Battle Infections," Proceedings of the National Academy of Sciences of the United States of America, Vol. 103, No. 24, 2006, pp. 8913-8914. http://dx.doi.org/10.1073/pnas.0603508103

[3] P. Elsbach, "What Is the Real Role of Antimicrobial Polypeptides That Can Mediate Several Other Inflammatory Responses?" Journal of Clinical Investigation, Vol. 111, No. 11, 2003, pp. 1643-1645.

[4] D. Yang, et al., "Multiple Roles of Antimicrobial Defensins, Cathelicidins, and Eosinophil-Derived Neurotoxin in Host Defense," Annual Review of Immunology, Vol. 22, 2004, pp. 181-215.

http://dx.doi.org/10.1146/annurev.immunol.22.012703.10 $\underline{4603}$

[5] R. E. Hancock, "Cationic Peptides: Effectors in Innate Immunity and Novel Antimicrobials," Lancet Infectious Diseases, Vol. 1, No. 3, 2001, pp. 156-164. http://dx.doi.org/10.1016/S1473-3099(01)00092-5

[6] M. C. Territo, et al., "Monocyte-Chemotactic Activity of 
Defensins from Human Neutrophils," Journal of Clinical Investigation, Vol. 84, No. 6, 1989, pp. 2017-2020. http://dx.doi.org/10.1172/JCI114394

[7] O. Chertov, et al., "Identification of Defensin-1, Defensin-2, and CAP37/Azurocidin as T-Cell Chemoattractant Proteins Released from Interleukin-8-Stimulated Neutrophils," Journal of Biological Chemistry, Vol. 271, No. 6, 1996, pp. 2935-2940.

http://dx.doi.org/10.1074/jbc.271.6.2935

[8] D. M. Bowdish, et al., "The Human Cationic Peptide LL-37 Induces Activation of the Extracellular SignalRegulated Kinase and p38 Kinase Pathways in Primary Human Monocytes," Journal of Immunology, Vol. 172, No. 6, 2004, pp. 3758-3765.

[9] J. Shi, et al., "A Novel Role for Defensins in Intestinal Homeostasis: Regulation of IL-1beta Secretion," Journal of Immunology, Vol. 179, No. 2, 2007, pp. 1245-1253.

[10] B. L. Kagan, T. Ganz and R. I. Lehrer, "Defensins: A Family of Antimicrobial and Cytotoxic Peptides," Toxicology, Vol. 87, No. 1-3, 1994, pp. 131-149.

http://dx.doi.org/10.1016/0300-483X(94)90158-9

[11] H. Jenssen, P. Hamill and R. E. Hancock, "Peptide Antimicrobial Agents," Clinical Microbiology Reviews, Vol. 19, No. 3, 2006, pp. 491-511. http://dx.doi.org/10.1128/CMR.00056-05

[12] Y. Q. Tang, et al., "A Cyclic Antimicrobial Peptide Produced in Primate Leukocytes by the Ligation of Two Truncated Alpha-Defensins," Science, Vol. 286, No. 5439, 1999, pp. 498-502.

http://dx.doi.org/10.1126/science.286.5439.498

[13] A. Fahlgren, et al., "Increased Expression of Antimicrobial Peptides and Lysozyme in Colonic Epithelial Cells of Patients with Ulcerative Colitis," Clinical \& Experimental Immunology, Vol. 131, No. 1, 2003, pp. 90-101. http://dx.doi.org/10.1046/j.1365-2249.2003.02035.x

[14] Y. Lai and R. L. Gallo, "AMPed up Immunity: How Antimicrobial Peptides Have Multiple Roles in Immune Defense," Trends in Immunology, Vol. 30, No. 3, 2009, pp. 131-141. http://dx.doi.org/10.1016/j.it.2008.12.003

[15] D. Yang, et al., "Beta-Defensins: Linking Innate and Adaptive Immunity through Dendritic and T Cell CCR6," Science, Vol. 286, No. 5439, 1999, pp. 525-528. http://dx.doi.org/10.1126/science.286.5439.525

[16] J. Harder, et al., "Differential Gene Induction of Human Beta-Defensins (hBD-1, -2, -3, and -4) in Keratinocytes Is Inhibited by Retinoic Acid," Journal of Investigative Dermatology, Vol. 123, No. 3, 2004, pp. 522-529. http://dx.doi.org/10.1111/j.0022-202X.2004.23234.x

[17] D. Proud, S. P. Sanders and S. Wiehler, "Human Rhinovirus Infection Induces Airway Epithelial Cell Production of Human Beta-Defensin 2 both in Vitro and in Vivo," Journal of Immunology, Vol. 172, No. 7, 2004, pp. 46374645.

[18] P. Vora, et al., "Beta-Defensin-2 Expression Is Regulated by TLR Signaling in Intestinal Epithelial Cells," Journal of Immunology, Vol. 173, No. 9, 2004, pp. 5398-5405.

[19] J. Harder, et al., "A Peptide Antibiotic from Human Skin," Nature, Vol. 387, No. 6636, 1997, p. 861. http://dx.doi.org/10.1038/43088
[20] J. Yu, et al., "Host Defense Peptide LL-37, in Synergy with Inflammatory Mediator IL-1beta, Augments Immune Responses by Multiple Pathways," Journal of Immunology, Vol. 179, No. 11, 2007, pp. 7684-7691.

[21] Y. Zheng, et al., "Cathelicidin LL-37 Induces the Generation of Reactive Oxygen Species and Release of Human Alpha-Defensins from Neutrophils," British Journal of Dermatology, Vol. 157, No. 6, 2007, pp. 1124-1131. http://dx.doi.org/10.1111/j.1365-2133.2007.08196.x

[22] K. M. Aberg, et al., "Psychological Stress Downregulates Epidermal Antimicrobial Peptide Expression and Increases Severity of Cutaneous Infections in Mice," Journal of Clinical Investigation, Vol. 117, No. 11, 2007, pp. 3339-3349. http://dx.doi.org/10.1172/JCI31726

[23] J. J. Smith, et al., "Cystic Fibrosis Airway Epithelia Fail to Kill Bacteria Because of Abnormal Airway Surface Fluid," Cell, Vol. 85, No. 2, 1996, pp. 229-236. http://dx.doi.org/10.1016/S0092-8674(00)81099-5

[24] M. J. Goldman, et al., "Human Beta-Defensin-1 Is a SaltSensitive Antibiotic in Lung That Is Inactivated in Cystic Fibrosis," Cell, Vol. 88, No. 4, 1997, pp. 553-560. http://dx.doi.org/10.1016/S0092-8674(00)81895-4

[25] L. C. Huang, et al., "In Vitro Activity of Human BetaDefensin 2 against Pseudomonas aeruginosa in the Presence of Tear Fluid," Antimicrobial Agents and Chemotherapy, Vol. 51, No. 11, 2007, pp. 3853-3860. http://dx.doi.org/10.1128/AAC.01317-06

[26] R. I. Lehrer and T. Ganz, "Antimicrobial Peptides in Mammalian and Insect Host Defence," Current Opinion in Immunology, Vol. 11, No. 1, 1999, pp. 23-27. http://dx.doi.org/10.1016/S0952-7915(99)80005-3

[27] G. Morrison, et al., "Characterization of the Mouse Beta Defensin 1, Defb1, Mutant Mouse Model," Infection and Immunity, Vol. 70, No. 6, 2002, pp. 3053-3060. http://dx.doi.org/10.1128/IAI.70.6.3053-3060.2002

[28] C. J. Kelly, et al., "Fundamental Role for HIF-1Alpha in Constitutive Expression of Human Beta Defensin-1," Mucosal Immunology, Vol. 6, 2013, pp. 1110-1118. http://dx.doi.org/10.1038/mi.2013.6

[29] H. Yu, et al., "The Novel Human Beta-Defensin 114 Regulates Lipopolysaccharide(LPS)-Mediated Inflammation and Protects Sperm from Motility Loss," Journal of Biological Chemistry, Vol. 288, No. 17, 2013, pp. 1227012282. http://dx.doi.org/10.1074/jbc.M112.411884

[30] D. Yang, et al., "Mammalian Defensins in Immunity: More Than Just Microbicidal," Trends in Immunology, Vol. 23, No. 6, 2002, pp. 291-296.

http://dx.doi.org/10.1016/S1471-4906(02)02246-9

[31] N. Funderburg, et al., "Human-Defensin-3 Activates Professional Antigen-Presenting Cells via Toll-Like Receptors 1 and 2," Proceedings of the National Academy of Sciences of the United States of America, Vol. 104, No. 47, 2007, pp. 18631-18635. http://dx.doi.org/10.1073/pnas.0702130104

[32] F. Niyonsaba, et al., "The Human Beta-Defensins (-1, -2, $-3,-4)$ and Cathelicidin LL-37 Induce IL-18 Secretion through p38 and ERK MAPK Activation in Primary Human Keratinocytes," Journal of Immunology, Vol. 175, No. 3, 2005, pp. 1776-1784. 
[33] J. W. Lillard, Jr., et al., "Mechanisms for Induction of Acquired Host Immunity by Neutrophil Peptide Defensins," Proceedings of the National Academy of Sciences of the United States of America, Vol. 96, No. 2, 1999, pp. 651-656.

http://dx.doi.org/10.1073/pnas.96.2.651

[34] A. Biragyn, et al., "Mediators of Innate Immunity that Target Immature, But Not Mature, Dendritic Cells Induce Antitumor Immunity When Genetically Fused with Nonimmunogenic Tumor Antigens," Journal of Immunology, Vol. 167, No. 11, 2001, pp. 6644-6653.

[35] K. Tani, et al., "Defensins Act as Potent Adjuvants That Promote Cellular and Humoral Immune Responses in Mice to a Lymphoma Idiotype and Carrier Antigens," International Immunology, Vol. 12, No. 5, 2000, pp. 691700.

[36] J. J. Oppenheim, A. Biragyn, L. W. Kwak and D. Yang, "Roles of Antimicrobial Peptides such as Defensins in Innate And Adaptive Immunity," Annals of the Rheumatic Diseases, Vol. 62, Suppl. 2, 2003, pp. ii17-ii21. http://dx.doi.org/10.1136/ard.62.suppl_2.ii17

[37] K. A. Brogden, M. Heidari, R. E. Sacco, D. Palmquist, J. M. Guthmiller, G. K. Johnson, H. P. Jia, B. F. Tack and P. B. McCray Jr., "Defensin-Induced Adaptive Immunity in Mice And Its Potential in Preventing Periodontal Disease," Oral Microbiology and Immunology, Vol. 18, No. 2, 2003, pp. 95-99. http://dx.doi.org/10.1034/j.1399-302X.2003.00047.x

[38] J. K. Kolls, P. B. McCray Jr. and Y. R. Chan, "Cytokine-Mediated Regulation of Antimicrobial Proteins," $\mathrm{Na}$ ture Reviews. Immunology, Vol. 8, No. 11, 2008, pp. 829-835.

[39] E. V. Acosta-Rodriguez, L. Rivino, J. Geginat, D. Jarrossay, M. Gattorno, A. Lanzavecchia, F. Sallusto and G. Napolitani, "Surface Phenotype and Antigenic Specificity of Human Interleukin 17-Producing T Helper Memory Cells," Nature Immunology, Vol. 8, No. 6, 2007, pp. 639646.

[40] V. Sass, U. Paga, A. Tossib, G. Bierbaumc and H. G. Sahl, "Mode of Action of Human Beta-Defensin 3 against Staphylococcus aureus and Transcriptional Analysis of Responses to Defensin Challenge," International Journal of Medical Microbiology, Vol. 298, No. 7-8, 2008, pp. 619-633. http://dx.doi.org/10.1016/j.ijmm.2008.01.011

[41] J. F. Sanchez, F. Wojcik, Y.-S. Yang, M.-P. Strub, J. M. Strub, A. Van Dorsselaer, M. Martin, R. Lehrer, T. Ganz, A. Chavanieu, B. Calas and A. Aumelasa, "Overexpression and Structural Study of the Cathelicidin Motif of the Protegrin-3 Precursor," Biochemistry, Vol. 41, No. 1, 2002, pp. 21-30. http://dx.doi.org/10.1021/bi010930a

[42] U. H. Durr, U. S. Sudheendra and A. Ramamoorthy, "LL-37, the Only Human Member of the Cathelicidin family of Antimicrobial Peptides," Biochimica et Biophysica Acta (BBA)-Biomembranes, Vol. 1758, No. 9, 2006, pp. 1408-1425. http://dx.doi.org/10.1016/j.bbamem.2006.03.030

[43] K. Edfeldt, B. Agerberth, M. E. Rottenberg, G. H. Gudmundsson, X. B. Wang, K. Mandal, Q. B. Xu and Z. Q. Yan, "Involvement of the Antimicrobial Peptide LL-37 in
Human Atherosclerosis," Arteriosclerosis, Thrombosis, and Vascular Biology, Vol. 26, No. 7, 2006, pp. 1551-1557. http://dx.doi.org/10.1161/01.ATV.0000223901.08459.57

[44] S. Yim, P. Dhawan, C. Ragunath, S. Christakos and G. Diamond, "Induction of Cathelicidin in Normal and CF Bronchial Epithelial Cells by 1,25-Dihydroxyvitamin $\mathrm{D}_{3}$," Journal of Cystic Fibrosis, Vol. 6, No. 6, 2007, pp. 403410. http://dx.doi.org/10.1016/j.jcf.2007.03.003

[45] M. Behuliak, R. Pálffy, R. Gardlík, J. Hodosy, L. Halčák and P. Celec, "Variability of Thiobarbituric Acid Reacting Substances in Saliva," Disease Markers, Vol. 26, No. 2, 2009, pp. 49-53. http://dx.doi.org/10.1155/2009/175683

[46] M. Chromek, Z. Slamová, P. Bergman, L. Kovács, L. Podracká, I. Ehrén, T. Hökfelt, G. H Gudmundsson, R. L Gallo, B. Agerberth and A. Brauner, "The Antimicrobial Peptide Cathelicidin Protects the Urinary Tract against Invasive Bacterial Infection," Nature Medicine, Vol. 12, No. 6, 2006, pp. 636-641. http://dx.doi.org/10.1038/nm1407

[47] M. Yoshioka, N. Fukuishi, Y. Kubo, H. Yamanobe, K. Ohsaki, Y. Kawasoe, M. Murata, A. Ishizumi, Y. Nishii, N. Matsui and M. Akagi, "Human Cathelicidin CAP18/LL-37 Changes Mast Cell Function toward Innate Immunity," Biological and Pharmaceutical Bulletin, Vol. 31, No. 2, 2008, pp. 212-216. http://dx.doi.org/10.1248/bpb.31.212

[48] G. S. Tjabringa, J. Aarbiou, D. K. Ninaber, J. W. Drijfhout, O. E. Sørensen, N. Borregaard, K. F. Rabe and P. S. Hiemstra, "The Antimicrobial Peptide LL-37 Activates Innate Immunity at the Airway Epithelial Surface by Transactivation of the Epidermal Growth Factor Receptor," Journal of Immunology, Vol. 171, No. 12, 2003, pp. 66906696.

[49] A. Nijnik and R. E. Hancock, "The Roles of Cathelicidin LL-37 in Immune Defences and Novel Clinical Applications," Current Opinion in Hematology, Vol. 16, No. 1, 2009, pp. 41-47. http://dx.doi.org/10.1097/MOH.0b013e32831ac517

[50] D. J. Davidson, A. J. Currie, G. S. Reid, D. M. Bowdish, K. L. MacDonald, R. C. Ma, R. E. Hancock and D. P. Speert, "The Cationic Antimicrobial Peptide LL-37 Modulates Dendritic Cell Differentiation and Dendritic Cell-Induced T Cell Polarization," Journal of Immunology, Vol. 172, No. 2, 2004, pp. 1146-1156.

[51] K. Kandler, R. Shaykhiev, P. Kleemann, F. Klescz, M. Lohoff, C. Vogelmeier and R. Bals, "The Anti-Microbial Peptide LL-37 Inhibits the Activation of Dendritic Cells by TLR Ligands," International Immunology, Vol. 18, No. 12, 2006, pp. 1729-1736. http://dx.doi.org/10.1093/intimm/dx1107

[52] M. Peric, S. Koglin, S. M. Kim, S. Morizane, R. Besch, J. C. Prinz, T. Ruzicka, R. L. Gallo and J. Schauber "IL-17A Enhances Vitamin D3-Induced Expression of Cathelicidin Antimicrobial Peptide in Human Keratinocytes," Journal of Immunology, Vol. 181, No. 12, 2008, pp. 8504-8512.

[53] Y. Rosenfeld, N. Papo and Y. Shai, "Endotoxin (Lipopolysaccharide) Neutralization by Innate Immunity Host-De- 
fense Peptides. Peptide Properties and Plausible Modes of Action," The Journal of Biological Chemistry, Vol. 281, No. 3, 2006, pp. 1636-1643. http://dx.doi.org/10.1074/jbc.M504327200

[54] C. Junkes, R. D. Harvey, K. D. Bruce, R. Dölling, M. Bagheri and M. Dathe, "Cyclic Antimicrobial R-, W-Rich Peptides: The Role of Peptide Structure and E. coli Outer and Inner Membranes in Activity and the Mode of Action," European Biophysics Journal, Vol. 40, No. 4. 2011, pp. 515-528. http://dx.doi.org/10.1007/s00249-011-0671-x

[55] P. N. Domadia, A. Bhunia, A. Ramamoorthy and S. Bhattacharjya, "Structure, Interactions, and AntiBacterial Activities of MSI-594 Derived Mutant Peptide MSI-594F5A in Lipopolysaccharide Micelles: Role of the Helical Hairpin Conformation in Outer-Membrane Permeabilization," Journal of American Chemical Society, Vol. 132, No. 51, 2010, pp. 18417-18428. http://dx.doi.org/10.1021/ja1083255

[56] M. R. Yeaman and N. Y. Yount, "Mechanisms of Antimicrobial Peptide Action and Resistance," Pharmacological Reviews, Vol. 55, No. 1, 2003, pp. 27-55. http://dx.doi.org/10.1124/pr.55.1.2

[57] S. E. Williams, T. I. Brown, A. Roghanian and J. M. Sallenave, "SLPI and Elafin: One Glove, Many Fingers," Clinical Science, Vol. 110, No. 1, 2006, pp. 21-35. http://dx.doi.org/10.1042/CS20050115

[58] J. M. Sallenave, "Antimicrobial Activity of Antiproteinases," Biochemical Society Transactions, Vol. 30, No. 2, 2002, pp. 111-115. http://dx.doi.org/10.1042/BST0300111

[59] S. A. Gomez, C. L. Argüelles, D. Guerrieri, N. L. Tateosian, N. O. Amiano, R. Slimovich, P. C. Maffia, E. Abbate, R. M. Musella, V. E. Garcia and H. E. Chuluyan, "Secretory Leukocyte Protease Inhibitor: A Secreted Pattern Recognition Receptor for Mycobacteria," American Journal of Respiratory and Critical Care Medicine, Vol. 179, No. 3, 2009, pp. 247-253. http://dx.doi.org/10.1164/rccm.200804-615OC

[60] J. Nishimura, H. Saiga, S. Sato, M. Okuyama, H. Kayama, H. Kuwata, S. Matsumoto, T. Nishida, Y. Sawa, S. Akira, Y. Yoshikai, M. Yamamoto and K. Takeda, "Potent Antimycobacterial Activity of Mouse Secretory Leukocyte Protease Inhibitor," Journal of Immunology, Vol. 180, No. 6, 2008, pp. 4032-4039.

[61] C. Verma, S. Seebah, S. M. Low, L. Zhou, S. P. Liu, J. Li and R. W. Beuerman, "Defensins: Antimicrobial Peptides for Therapeutic Development," Biotechnology Journal, Vol. 2, No. 11, 2007, pp. 1353-1359. http://dx.doi.org/10.1002/biot.200700148

[62] H. Saitoh, T. Masuda, S. Shimura, T. Fushimi and K. Shirato, "Secretion and Gene Expression of Secretory Leukocyte Protease Inhibitor by Human Airway Submucosal Glands," American Journal of Physiology. Lung Cellular and Molecular Physiology, Vol. 280, No. 1, 2001, pp. L79-L87.

[63] S. van Wetering, A. C. van der Linden, M. A. van Sterkenburg, K. F. Rabe, J. Schalkwijk and P. S. Hiemstra, "Regulation of Secretory Leukocyte Proteinase Inhibitor
(SLPI) Production by Human Bronchial Epithelial Cells: Increase of Cell-Associated SLPI by Neutrophil Elastase," Journal of Investigative Medicine,. Vol. 48, No. 5, 2000, pp. 359-366.

[64] B. L. Luo, R. C. Niu, J. T. Feng, C. P. Hu, X. Y. Xie and L. J. Ma, "Downregulation of Secretory Leukocyte Proteinase Inhibitor in Chronic Obstructive Lung Disease: The Role of TGF-beta/Smads Signaling Pathways," Archives of Medical Research, Vol. 39, No. 4, 2008, pp. 388-396. http://dx.doi.org/10.1016/j.arcmed.2008.02.002

[65] Y. Higashimoto, Y. Yamagata, T. Iwata, T. Ishiguchi, M. Okada, M. Masuda, H. Satoh and H. Itoh, "Adenoviral E1A Suppresses Secretory Leukoprotease Inhibitor and Elafin Secretion in Human Alveolar Epithelial Cells and Bronchial Epithelial Cells," Respiration, Vol. 72, No. 6, 2005, pp. 629-635.

[66] F. Jaumann, A. Elssner, G. Mazur, S. Dobmann and C. Vogelmeier, "Transforming Growth Factor-Betal Is a Potent Inhibitor of Secretory Leukoprotease Inhibitor exPression in a Bronchial Epithelial Cell Line. Munich Lung Transplant Group," European Respiratory Journal, Vol. 15, No. 6, 2000, pp. 1052-1057. http://dx.doi.org/10.1034/j.1399-3003.2000.01513.x

[67] A. H. Ding, H. W. Yu, J. X. Yang, S. P. Shi and S. Ehrt, "Induction of Macrophage-Derived SLPI by Mycobacterium Tuberculosis Depends on TLR2 but Not MyD88," Immunology, Vol. 116, No. 3, 2005, pp. 381-389. http://dx.doi.org/10.1111/j.1365-2567.2005.02238.x

[68] M. L. Zani, A. Tanga, A. Saidi, H. Serrano, S. DalletChoisy, K. Baranger and T. Moreau, "SLPI and Trappin-2 as Therapeutic Agents to Target Airway Serine Proteases in Inflammatory Lung Diseases: Current and Future Directions," Biochemical Society Transactions, Vol. 39, No. 5, 2011, pp. 1441-1446. http://dx.doi.org/10.1042/BST0391441

[69] A. L. Jendeberg, K. Stralin and O. Hultgren, "Antimicrobial Peptide Plasma Concentrations in Patients with Community-Acquired Pneumonia," Scandinavian Journal of Infectious Diseases, Vol. 45, No. 6, 2013, pp. 432-437.

http://dx.doi.org/10.3109/00365548.2012.760844

[70] P. Mallia, et al., "Rhinovirus Infection Induces Degradation of Antimicrobial Peptides and Secondary Bacterial Infection in Chronic Obstructive Pulmonary Disease," American Journal of Respiratory and Critical Care Medicine, Vol. 186, No. 11, 2012, pp. 1117-1124. http://dx.doi.org/10.1164/rccm.201205-0806OC

[71] T. Moreau, K. Baranger, S. Dadé, S. Dallet-Choisy, N. Guyot and M. L. Zan, "Multifaceted Roles of Human Elafin and Secretory Leukocyte Proteinase Inhibitor (SLPI), Two Serine Protease Inhibitors of the Chelonianin Family," Biochimie, Vol. 90, No. 2, 2008, pp. 284-295. http://dx.doi.org/10.1016/j.biochi.2007.09.007

[72] S. Weldon and C. C. Taggart, "Innate Host Defense Functions of Secretory Leucoprotease Inhibitor," Experimental Lung Research, Vol. 33, No. 10, 2007, pp. 485-491. http://dx.doi.org/10.1080/01902140701756547

[73] J. X. Yang, J. Zhu, D. X. Sun and A. H. Ding, "Suppression of Macrophage Responses to Bacterial Lipopolysac- 
charide (LPS) by Secretory Leukocyte Protease Inhibitor (SLPI) Is Independent of Its Anti-Protease Function," Biochimica et Biophysica Acta, Vol. 1745, No. 3, 2005, pp. 310-317.

http://dx.doi.org/10.1016/j.bbamcr.2005.07.006

[74] F. Jin, C. F. Nathan, D. Radzioch and A. Ding, "Lipopolysaccharide-Related Stimuli Induce Expression of the Secretory Leukocyte Protease Inhibitor, a Macrophage-Derived Lipopolysaccharide Inhibitor," Infection and Immunity, Vol. 66, No. 6, 1998, pp. 2447-2452.

[75] A. B. Lentsch, J. A Jordan, B. J. Czermak, K. M. Diehl, E. M. Younkin, V. Sarma and P. A. Ward, "Inhibition of NF-kappaB Activation and Augmentation of IkappaBbeta by Secretory Leukocyte Protease Inhibitor during Lung Inflammation," The American Journal of Pathology, Vol. 154, No. 1, 1999, pp. 239-247. http://dx.doi.org/10.1016/S0002-9440(10)65270-4

[76] C. C. Taggart, S. A. Cryan, S. Weldon, A. Gibbons, C. M. Greene, E. Kelly, T. B. Low, S. J. O’Neill and N. G. McElvaney, "Secretory Leucoprotease Inhibitor Binds to NF-kappaB Binding Sites in Monocytes and InHibits p65 Binding," The Journal of Experimental Medicine, Vol. 202, No. 12, 2005, pp. 1659-1668.

http://dx.doi.org/10.1084/jem.20050768

[77] G. S. Ashcroft, K. J. Lei, W. W. Jin, G. Longenecker, A. B. Kulkarni, T. Greenwell-Wild, H. Hale-Donze1, G. McGrady, X. Y. Song and S. M. Wahl, "Secretory Leukocyte Protease Inhibitor Mediates Non-Redundant Functions Necessary for Normal Wound Healing," Nature Medicine, Vol. 6, No.10, 2000, pp. 1147-1153. http://dx.doi.org/10.1038/80489

[78] J. N. Samsom, A. P. van der Marel, L. A. van Berkel, J. M. van Helvoort, Y. Simons-Oosterhuis, W. Jansen, M. Greuter, R. L. Nelissen, C. M. Meeuwisse, E. E. Nieuwenhuis, R. E. Mebius and G. Kraal, "Secretory Leukoprotease Inhibitor in Mucosal Lymph Node Dendritic Cells Regulates the Threshold for Mucosal Tolerance," Journal of Immunology, Vol. 179, No. 10, 2007, pp. 6588-6595.

[79] W. Xu, A. Chiu, A. Chadburn, M. Shan, M. Buldys, A. Ding, D. M. Knowles, P. A. Santini and A. Cerutti, "Epithelial Cells Trigger Frontline Immunoglobulin Class Switching through a Pathway Regulated by the Inhibitor SLPI," Nature Immunology, Vol. 8, No. 3, 2007, pp. 294303.

[80] A. Nakamura, Y. Mori, K. Hagiwara, T. Suzuki, T. Sakakibara, T. Kikuchi, T. Igarashi, M. Ebina, T. Abe, J. Miyazaki, T. Takai and T. Nukiwa, "Increased Susceptibility to LPS-Induced Endotoxin Shock in Secretory Leukoprotease Inhibitor (SLPI)-Deficient Mice," Journal of Experimental Medicine, Vol. 197, No. 5, 2003, pp. 669-674. http://dx.doi.org/10.1084/jem.20021824

[81] A. Roghanian, S. E. Williams, T. A. Sheldrake, T. I. Brown, K. Oberheim, Z. Xing, S. E. M. Howie and J. M. Sallenave, "The Antimicrobial/Elastase Inhibitor Elafin Regulates Lung Dendritic Cells and Adaptive Immunity," American Journal of Respiratory Cell and Molecular Biology, Vol. 34, No. 5, 2006, pp. 634-642. http://dx.doi.org/10.1165/rcmb.2005-0405OC

[82] Y. Zhang, D. L. DeWitt, T. B. McNeely, S. M. Wahl and
L. M. Wahl, "Secretory Leukocyte Protease Inhibitor Suppresses the Production of Monocyte Prostaglandin H Synthase-2, Prostaglandin E2, and Matrix Metalloproteinases," Journal of Clinical Investigation, Vol. 99, No. 5, 1997, pp. 894-900. http://dx.doi.org/10.1172/JCI119254

[83] X. Y. Song, Li. Zenga, W. W. Jina, J. Thompsona, D. E. Mizela, K. J. Leia, R. C. Billinghurstb, A. R. Pooleb and S. M. Wahl, "Secretory Leukocyte Protease Inhibitor Suppresses the Inflammation and Joint Damage of Bacterial Cell Wall-Induced Arthritis," Journal of Experimental Medicine, Vol. 190, No. 4, 1999, pp. 535-542. http://dx.doi.org/10.1084/jem.190.4.535

[84] J. Zhu, C. Nathan, W. W. Jin, D. Sim, G. S. Ashcroft, S. M. Wahl, L. Lacomis, H. Erdjument-Bromage, P. Tempst, C. D. Wright and A. H. Ding, "Conversion of Proepithelin to Epithelins: Roles of SLPI and Elastase in Host Defense and Wound Repair," Cell, Vol. 111, No. 6, 2002, pp. 867-878.

http://dx.doi.org/10.1016/S0092-8674(02)01141-8

[85] N. Angelov, N. Moutsopoulos, M. J. Jeong, S. Nares, G. Ashcroft and S. M. Wahl, "Aberrant Mucosal Wound Repair in the Absence of Secretory Leukocyte Protease Inhibitor," Thrombosis and Haemostasis, Vol. 92, No. 2, 2004, pp. 288-297.

[86] E. Fakioglu, S. S. Wilson, P. M. M. Mesquita, E. Hazrati1, N. Cheshenko, J. A. Blaho and B. C. Herold, "Herpes Simplex Virus Downregulates Secretory Leukocyte Protease Inhibitor: A Novel Immune Evasion Mechanism," Journal of Virology, Vol. 82, No. 19, 2008, pp. 9337-9344.

http://dx.doi.org/10.1128/JVI.00603-08

[87] M. Hoffmann, E. S. Quabius, S. Tribius, L. Hebebrand, T. Görögh, G. Halec, T. Kahn, J. Hedderich, C. Röcken, J. Haag, T. Waterboer, M. Schmitt, A. R. Giuliano and W. M. Kast, "Human Papillomavirus Infection in Head and Neck Cancer: The Role of the Secretory Leukocyte Protease Inhibitor," Oncology Reports, Vol. 29, No. 5, 2013, pp. 1962-1968.

[88] J. S. Huppert, B. Huang, C. Chen, H. Y. Dawood and R. N. Fichorova, "Clinical Evidence for the Role of Trichomonas Vaginalis in Regulation of Secretory Leukocyte Protease Inhibitor in the Female Genital Tract," The Journal of Infectious Diseases, Vol. 207, No. 9, 2013, pp. 1462-1470. http://dx.doi.org/10.1093/infdis/jit039

[89] T. B. McNeely, D. C. Shugars, M. Rosendahl, C. Tucker, S. P. Eisenberg and S. M. Wahl, "Inhibition Of Human Immunodeficiency Virus Type 1 Infectivity by Secretory Leukocyte Protease Inhibitor Occurs Prior to Viral Reverse Transcription," Blood, Vol. 90, No. 3, 1997, pp. 1141-1149.

[90] C. C. Tseng and C. P. Tseng, "Identification of a Novel Secretory Leukocyte Protease Inhibitor-Binding Protein Involved in Membrane Phospholipid Movement," FEBS Letters, Vol. 475, No. 3, 2000, pp. 232-236. http://dx.doi.org/10.1016/S0014-5793(00)01700-2

[91] G. Ma, T. Greenwell-Wild, K. J. Lei, W. W. Jin, J. Swisher, N. Hardegen, C. T. Wild and S. M. Wahl, "Secretory Leukocyte Protease Inhibitor Binds to Annexin II, 
a Cofactor for Macrophage HIV-1 Infection," Journal of Experimental Medicine, Vol. 200, No. 10, 2004, pp. 13371346. http://dx.doi.org/10.1084/jem.20041115

[92] K. Pillay, A. Coutsoudis, A. K. Agadzi-Naqvi, L. Kuhn, H. M. Coovadia and E. N. Janoff, "Secretory Leukocyte Protease Inhibitor in Vaginal Fluids And Perinatal Human Immunodeficiency Virus Type 1 Transmission," The Journal of Infectious Diseases, Vol. 183, No. 4, 2001, pp. 653-656. http://dx.doi.org/10.1086/318535

[93] S. M. Iqbal, et al., "Elevated Elafin/Trappin-2 in The Female Genital Tract Is Associated with Protection Against HIV Acquisition," AIDS, Vol. 23, No. 13, 2009, pp. 1669-1677.

http://dx.doi.org/10.1097/QAD.0b013e32832ea643

[94] D. M. Waisman, “Annexin II Tetramer: Structure and Function," Molecular and Cellular Biochemistry, Vol. 149-150, No. 1, 1995, pp. 301-322. http://dx.doi.org/10.1007/BF01076592

[95] U. Rescher and V. Gerke, "S100A10/p11: Family, Friends and Functions," Pflügers Archiv, Vol. 455, No. 4, 2008, pp. 575-582. http://dx.doi.org/10.1007/s00424-007-0313-4

[96] E. Pena-Alonso, et al., "Annexin A2 Localizes to the Basal Epithelial Layer and Is Down-Regulated in Dysplasia and Head and Neck Squamous Cell Carcinoma," Cancer Letters, Vol. 263, No. 1, 2008, pp. 89-98. http://dx.doi.org/10.1016/j.canlet.2007.12.029

[97] A. W. Woodham, D. M. Da Silva, J. G. Skeate, A. B. Raff, M. R. Ambroso, H. E. Brand, J. M. Isas, R. Langen and W. M. Kast, "The S100A10 Subunit of the Annexin A2 Heterotetramer Facilitates L2-Mediated Human Papillomavirus Infection," PLoS ONE, Vol. 7, No. 8, 2012, Article ID: e43519. http://dx.doi.org/10.1371/journal.pone.0043519

[98] R. Medzhitov and C. A. Janeway Jr., "Decoding the Patterns of Self and Nonself by the Innate Immune System," Science, Vol. 296, No. 5566, 2002. pp. 298-300. http://dx.doi.org/10.1126/science.1068883

[99] T. Andrews and K. E. Sullivan, "Infections in Patients with Inherited Defects in Phagocytic Function," Clinical Microbiology Reviews, Vol. 16, No. 4, 2003, pp. 597-621. http://dx.doi.org/10.1128/CMR.16.4.597-621.2003 